Short report

\title{
Anterior horn cell dysfunction in Alzheimer's disease
}

\author{
MYFANWY THOMAS, JOHN P BALLANTYNE, STIG HANSEN, \\ ANDREW I WEIR, DAVID DOYLE \\ From the Departments of Neurology and Neuropathology, Institute of Neurological Sciences, Southern \\ General Hospital and the Department of Clinical Physics and Bio-engineering, Glasgow. Scotland
}

SUMMARY Electrophysiological studies were undertaken on 29 patients with Alzheimer's Disease. A reduction in the number of functioning motor units was found in the extensor digitorum brevis muscle. The electrophysiological parameters of the motor unit potentials were increased compared to control values. Four of seven muscle biopsies showed abnormalities ranging from mild to severe. The results suggest dysfunction in the lower motor neurone in this disease.

There is a considerable literature on the clinical manifestations, intellectual deterioration and neuropathology of Alzheimer s Disease. ${ }^{1-3}$ Little attention has been given to possible peripheral electrophysiological changes despite the late appearance of muscle atrophy and muscular twitching. The present investigation was designed to test the hypothesis that there is a disturbance of lower motor neuron function in this disorder. To this end we have employed our techniques for the estimation of motor unit numbers and analysis of motor unit potential parameters in the extensor digitorum brevis muscles of a group of patients with Alzheimer's Disease. In addition, fastest motor nerve conduction velocities and shortest distal motor latencies were measured in the lateral popliteal nerves. Motor and sensory studies were undertaken in an ulnar nerve in a number of patients. Informed consent was obtained from the reiatives of seven patients (four male, three female) on whom open biopsy of the vastus medialis muscle was performed under local anaesthesia.

\section{Methods}

The composition and placement of the surface recording electrodes over the extensor digitorum brevis muscle, the properties of the stimulating electrodes over the anterior tibial nerve at the ankle and the details of the rate and strength of stimulation used to evoke motor unit poten-

Address for reprint requests: Dr Myfanwy Thomas, Department of Neurology, Southern General Hospital, Glasgow G51 4TF, Scotland.

Received 12 March 1981 and in revised form 18 May 1981 Accepted 7 June 1981 tials have been described. ${ }^{4}$ The amplification and display systems, the computer handling of data for the estimation of motor unit numbers in the extensor digitorum brevis muscle ${ }^{4}$ and the computer derivation of the parameters of the electrically evoked motor unit potentials have also been reported..$^{5}$

Briefly, motor unit potentials recorded from surface electrodes over the extensor digitorum brevis muscle are evoked sequentially by finely graded incremental stimulation of the anterior tibial nerve at the ankle. Recruitment of up to 15 motor units can be recognised by a combination of visual and computer analysis of the muscle action potential increments displayed on the oscilloscope screen. The first motor unit potential is displayed in isolation on the oscilloscope. The potential of the second is incorporated in a compound muscle action potential containing motor unit potentials 1 and 2 . As each new petential is added to the preceding one, the compound muscle action potential so constituted is stored in a computer memory (template). Template 1 contains motor unit potential 1 , template 2 contains the sum of motor unit potentials 1 and 2 , template 3 contains the sum of motor unit potentials 1,2 and 3 , and so on. Up to 15 templates can be stored. The number of motor units in the extensor digitorum brevis muscle is calculated from the formula:

$$
\mathrm{MUN}=[\mathrm{A}(\mathrm{M}) / \mathrm{A}(\mathrm{N})] \cdot \mathrm{N}
$$

where MUN is the motor unit number, $A(M)$ is the area of the supramaximally evoked muscle action potential and $A(N)$ is the area of the compound muscle action potential containing $\mathbf{N}$ motor unit potentials.

By a process of template subtraction, the computer also displays the first and sequentially recruited motor unit potentials in isolation. For example, subtraction of template 1 from template 2 will leave motor unit potential 2 in isolation, subtraction of template 2 from template 3 will leave motor unit potential 3 in isolation and so on. 
The latency, duration, amplitude and area of each individual motor unit potential is then measured. Amplitudes and areas are provided by the computer, while latencies and durations are measured manually from a computer printout. All potential recordings are from surface electrodes over the extensor digitorum brevis muscle.

The fastest motor nerve conduction velocities in the lateral popliteal nerve (knee to ankle segment) and shortest distal motor latencies (anterior tibial nerve at the ankle to extensor digitorum brevis muscle) were measured from the same surface electrodes over the extensor digitorum brevis muscle. The fastest motor nerve conduction velocities and shortest distal motor latencies were also measured in one ulnar nerve in the below elbow to wrist segment. The motor response evoked by surface stimulation of the ulnar nerve was recorded from silver strip electrodes over the hypothenar eminence. Sensory nerve action potentials from stimulation of the little finger were recorded orthodromically over the ulnar nerve at the wrist from the electrodes used for motor stimulation.

All investigations were undertaken in a thermostatically controlled room and limb temperature was maintained at $33^{\circ} \mathrm{C} \pm 1{ }^{\circ} \mathrm{C}$.

The muscle biopsies were examined by light microscopy using routine staining techniques for innervation (silver impregnation, cholinesterase and methylene blue) and for the presence of succinic dehydrogenase and myosinATPase activity.

\section{Patients and control subjects}

In the patients, 14 male and 15 female, the following clinical features were present. There was a history of a gradual deterioration over 1-6 years in memory, intellect and ability to pursue employment, household tasks or handle finances. Insight was lacking except in the mildest cases. The personality was preserved in all but the most severely affected. All were dysphasic in varying degrees and displayed an inability to manipulate acquired knowledge and learn new material. All were normotensive. All had CT scans showing diffuse atrophy in varying degree. All patients had been screened for evidence of structual, metabolic or non-metastatic causes of dementia.

There were 19 control subjects (mean age 57.4 $\pm 10 \cdot 4$ years) (table). All were free of neurological disease and were drawn from the staff and their relatives of the Institute of Neurological Sciences, Glasgow.

Results are expressed as the mean \pm one standard deviation. Students' $t$ test was used for statistical analysis.

\section{Results}

\section{MOTOR UNIT NUMBERS}

There was a reduction in the mean number of functioning motor units in the Alzheimer group compared to the controls (table).

\section{SHORTEST DISTAL MOTOR LATENCY AND \\ FASTEST MOTOR NERVE CONDUCTION \\ VELOCITY}

Mean shortest distal motor latency in the Alzheimer patients was prolonged (table). The mean fastest motor nerve conduction velocity was not different from the control mean (table).

Table Age, shortest distal motor latency, fastest motor nerve conduction velocity, motor unit number and motor unit potential latency, duration, amplitude and area in control subjects and patients with Alzheimer's disease

\begin{tabular}{|c|c|c|c|c|}
\hline & $n$ & Mean & $S D$ & $p$ \\
\hline \multicolumn{5}{|l|}{ Age (years) } \\
\hline Control & 19 & $57 \cdot 4$ & $10 \cdot 4$ & - \\
\hline Alzheimer & 29 & $57 \cdot 7$ & $5 \cdot 6$ & NS* \\
\hline \multicolumn{5}{|c|}{ Shortest distal motor latency (ms) } \\
\hline Control & 19 & $3 \cdot 62$ & $0 \cdot 52$ & - \\
\hline Alzheimer & 29 & $4 \cdot 39$ & $1 \cdot 06$ & $<0.005$ \\
\hline \multicolumn{5}{|c|}{ Fastest motor nerve conduction velocity $(\mathrm{m} / \mathrm{s})$} \\
\hline Control & 11 & $46 \cdot 9$ & $5 \cdot 1$ & - \\
\hline Alzheimer & 29 & $46 \cdot 6$ & $3 \cdot 5$ & NS* \\
\hline \multicolumn{5}{|c|}{ Motor unit number } \\
\hline Control & 19 & $174 \cdot 8$ & $75 \cdot 0$ & - \\
\hline Alzheimer & 29 & $103 \cdot 9$ & $77 \cdot 6$ & $<0.005$ \\
\hline \multicolumn{5}{|c|}{ Motor unit potential latency (ms) } \\
\hline Control & 125 & $4 \cdot 82$ & $1 \cdot 52$ & - \\
\hline Alzheimer & 178 & $5 \cdot 92$ & $2 \cdot 08$ & $<0.0001$ \\
\hline \multicolumn{5}{|c|}{ Motor unit potential duration (ms) } \\
\hline Control & 125 & $9 \cdot 34$ & $2 \cdot 02$ & - \\
\hline Alzheimer & 178 & $10 \cdot 22$ & $1 \cdot 78$ & $<0.0001$ \\
\hline \multicolumn{5}{|c|}{ Motor unit potential amplitude $(\mu \mathrm{V})$} \\
\hline Control & 125 & $68 \cdot 2$ & $38 \cdot 2$ & 一 \\
\hline Alzheimer & 178 & $137 \cdot 8$ & $174 \cdot 0$ & $<0.0001$ \\
\hline \multicolumn{5}{|c|}{ Motor unit potential area (area units) } \\
\hline Control & 125 & 18.9 & $9 \cdot 9$ & - \\
\hline Alzheimer & 178 & $37 \cdot 5$ & $47 \cdot 7$ & $<0.0001$ \\
\hline
\end{tabular}

*NS: not significant. 
MOTOR UNIT POTENTIAL PARAMETERS

There were increases in the mean latency, duration, amplitude and area of the motor unit potentials in patients with Alzheimer's Disease (table).

ULNAR NERVE STUDIES

There was no difference in mean shortest distal motor latency, fastest motor nerve conduction velocity, sensory nerve conduction velocity or sensory nerve action potential amplitude between the Alzheimer and control groups.

\section{MUSCLE BIOPSIES}

Three biopsies (all from male patients) showed no abnormalities. Of the remainder, one biopsy showed severe type- 2 muscle fibre atrophy and solitary completely atrophic muscle fibres of both main histochemical types. A second showed severe type-2 muscle fibre atiophy. The third had an abnormal preponderance of type- 2 fibres and mild atrophy of some of those. The fourth showed only mild type-2 atrophy. In none of the cases was there any abnormality of motor end-plates or neuromuscular innervation.

\section{Discussion}

There was a reduction in the number of functioning motor axons in the extensor digitorum brevis muscle of patients with Alzheimer's disease compared to the control group. This may be a consequence of demyelinating block of conduction, or of axonal or anterior horn cell degeneration. In our earlier studies of neuropathies with a recognised demyelinating component (Guillain-Barré syndrome ${ }^{6}$ and diabetic neuropathy ${ }^{7}$ ) we have found a moderate increase in the area of surviving motor unit potential indicating the presence of collateral re-innervation by viable motor axons. In the predominantly axonal neuropathies of uraemia ${ }^{8}$ and chronic alcohol intoxication $^{9}$ the increase in mean motor unit potential area is less marked. Only in the neuronopathy of motor neurone disease ${ }^{10}$ have we found increases in areas of the motor unit potentials comparable to those in the present study. Furthermore the fastest motor nerve conduction velocity in the lateral popliteal nerves and the motor and sensory parameters in the ulnar nerves in the Alzheimer patients were within the normal range. Mean shortest distal motor latency in the lateral popliteal nerve however was prolonged. These findings suggest that the peripheral motor nerve fibres that remain functional proximal to the point of branching in the muscle are conducting at physiological rates. There was no pathological slowing of conduction in motor and sensory axons. These results are qualitatively similar to those in motor neurone disease. There are other parallels: muscular twitchings have been described in Alzheimer's disease. ${ }^{11} \mathrm{We}$ have observed fasciculations during our electrophysiological studies in a number of patients but have not quantified this data further.

We do not conclude that patients with Alzheimer's disease also have motor neurone disease but that the changes in motor unit numbers and motor unit potential parameters in this study are comparable to those we have found in patients with motor neurone disease and differ from the results in our studies of peripheral neuropathies.

The abnormalities in the muscle biopsies could be related to disuse atrophy. However since all patients were ambulant, many with motor restlessness, inactivity is unlikely to have contributed to these appearances. There is no evidence to support a myopathic cause, but the changes are compatible with anterior horn cell or peripheral nerve dysfunction. ${ }^{12}$

We are grateful to the staff of the Neurology Department and their patients for taking part in this study. Our thanks are due to Mrs J Henderson for secretarial assistance. Dr Weir is a Wellcome Senior Clinical Research Fellow.

\section{References}

${ }^{1}$ Grunthal E. Uber die Alzheimerche Krankheit. Eine histopathologish-kliniche Studie. $Z$ ges Neurol Psychiat 1926;101:128-57.

${ }^{2}$ Herz E, Funfgeld E. Zur Klinik und Pathologie der Alzheimerschen Krankheit. I. Klinische Darstellung. Arch Psychiatry 1928;8:633-45.

${ }^{3}$ Hughes W. Alzheimer's Disease. Geron Clin 1970;12: 129-48.

${ }^{4}$ Ballantyne JP, Hansen S. A new method for the estimation of the number of motor units in a muscle. 1 Control subjects and patients with myasthenia gravis. J Neurol Neurosurg Psychiatry 1974;37:90715.

s Ballantyne JP, Hansen S. Computer method for the analysis of evoked motor unit potentials. 1 Control subjects and patients with myasthenia gravis. $J$ Neurol Neurosurg Psychiatry 1974;37:1187-94.

${ }^{6}$ Martinez-Figueroa A, Hansen S, Ballantyne JP. A quantitative electrophysiological study of acute idiopathic polyneuritis. $J$ Neurol Neurosurg Psychiatry 1977;40:156-61.

${ }^{7}$ Hansen S, Ballantyne JP. Axonal dysfunction in the neuropathy of diabetes mellitus: A quantitative electrophysiological study. $J$ Neurol Neurosurg Psychiatry 1977;40:555-64.

${ }^{8}$ Hansen S, Ballantyne JP. A quantitative electrophysiological study of uraemic neuropathy. $J$ Neurol Neurosurg Psychiatry 1978;41:128-34. 
${ }^{9}$ Ballantyne JP, Hansen S, Weir A, Whitehead JRG, Mullin PJ. Quantitative electrophysiclogical study of alcoholic neuropathy. $J$ Neurol Neurosurg Psychiatry 1980;43:427-32.

${ }^{10}$ Hansen S, Ballantyne JP. A quantitative electrophysiological study of motor neurone disease. $J$ Neurol Neurosurg Psychiatry 1978;41:773-83.
${ }^{11}$ Jacob H. Muscular twitchings in Alzheimer's Disease. CIBA Foundation Symposium on Alzheimer's Disease 1970:75-93.

12 Brooke MH, Engel WK. The histographic analysis of human muscle biopsies. 2. Diseases of upper and lower motor neurones. Neurology (Minneap) 1969; 19:378-93. 